\title{
Understanding the role of dopants in the thermoelectric properties of $\mathrm{PbSe}$
}

\author{
Chhatrasal Gayner ${ }^{1}$, Malay K. Das ${ }^{2}$ and Kamal K Kar ${ }^{1,2^{*}}$ \\ ${ }^{1}$ Advanced Nanoengineering Materials Laboratory, Materials Science Programme, Indian Institute of \\ Technology Kanpur, Kanpur-208016, India \\ ${ }^{2}$ Advanced Nanoengineering Materials Laboratory, Department of Mechanical Engineering, Indian \\ Institute of Technology Kanpur, Kanpur-208016, India \\ *Email:kamalkk@iitk.ac.in
}

Interestingly, thermoelectricity is known to convert the waste heat into electricity. The thermoelectric efficiency is enumerated by dimensionless figure of merit (ZT), which is related to Seebeck coefficient $(\alpha)$, electrical conductivity $(\sigma)$ and thermal conductivity $(\kappa)$ by the relation $\mathrm{ZT}=\left(\alpha^{2} \sigma / \kappa\right) \mathrm{T}$ [1-2]. Widely studied PbSe has high Seebeck coefficient and the past studies suggested that, $\mathrm{Na}, \mathrm{K}, \mathrm{Tl}, \mathrm{Ag}$ are the effective hole dominate dopants, whereas doping through $\mathrm{Cr}, \mathrm{Ga}$, In, B induce the electron concentration in $\mathrm{PbSe}$, making it n-type [1-3]. In relation to this, we have synthesized $\mathrm{PbSe}: \mathrm{M}_{\mathrm{x}}(\mathrm{M} \sim \mathrm{Al}, \mathrm{Ni}, \mathrm{Cu} ; \mathrm{x} \sim 0.02)$ via solid state synthesis. The synthesis was carried out in a vacuumsealed quartz ampoule at $1373 \mathrm{~K}$. The as-synthesized samples were polished before further analysis for thermoelectric performances.
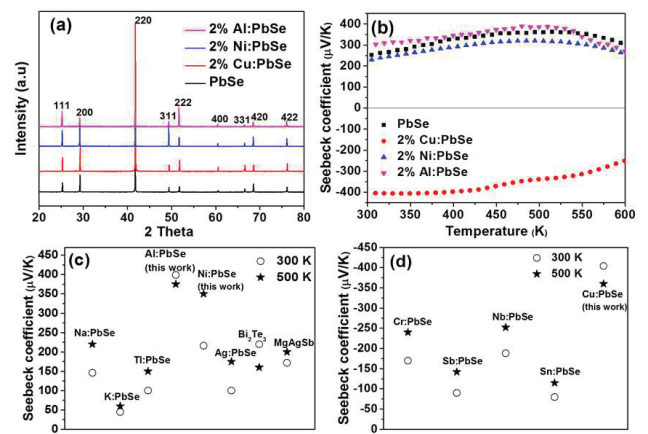

Figure 1: (a) XRD of $\mathrm{PbSe}: \mathrm{M}_{\mathrm{x}}$ (M: $\mathrm{Al}, \mathrm{Ni}, \mathrm{Cu} ; 0 \leq \mathrm{x} \leq 0.02$ ), (b) Temperature dependence of Seebeck coefficient of PbSe:Mx (M: Al, Ni, Cu; $0 \leq x \leq 0.02$ ), (c \& d) Comparison of Seebeck coefficient with other reports

Figure 1 (a) shows the cubic rock-salt structure with most intense reflection at $2 \theta$ of $42.2^{\circ}$ (for 220), having the close match with other references [JCPDS 06-0354] [3]. The $\alpha$ of bare $\mathrm{PbSe} \sim 254 \mu \mathrm{V} / \mathrm{K}, \mathrm{PbSe}: 2 \% \mathrm{Al} \sim 302$ $\mu \mathrm{V} / \mathrm{K}, \mathrm{PbSe}: 2 \% \mathrm{Ni} \sim 236 \mu \mathrm{V} / \mathrm{K}, \mathrm{PbSe}: 2 \% \mathrm{Cu} \sim-397 \mu \mathrm{V} / \mathrm{K}$ represents the individual role of dopants $\left(\alpha_{\mathrm{Cu}}>\alpha_{\mathrm{Al}}>\alpha_{\mathrm{Ni}}\right)$, as can be seen in Figure 1 (b). In such case, the nature of dopant as well as the shifting of fermi energy $\left(E_{f}\right)$ level inside the conduction/valence band conveniently impact over the Seebeck coefficient. Interestingly, the obtained Seebeck coefficient is comparatively larger than other elemental doped $\mathrm{PbSe}$, as shown in Figure 1 (c and d). Furthermore, $\mathrm{Cu}$ acts as a donor in $\mathrm{PbSe}$, while $\mathrm{Al}$ and $\mathrm{Ni}$ are acting as accepter. A nearly linear temperature dependence of Seebeck coefficient indicates typical degenerate conduction in $\mathrm{PbSe}_{\mathrm{x}}(\mathrm{M}: \mathrm{Al}, \mathrm{Ni}$; $0 \leq \mathrm{x} \leq 0.02$ ).

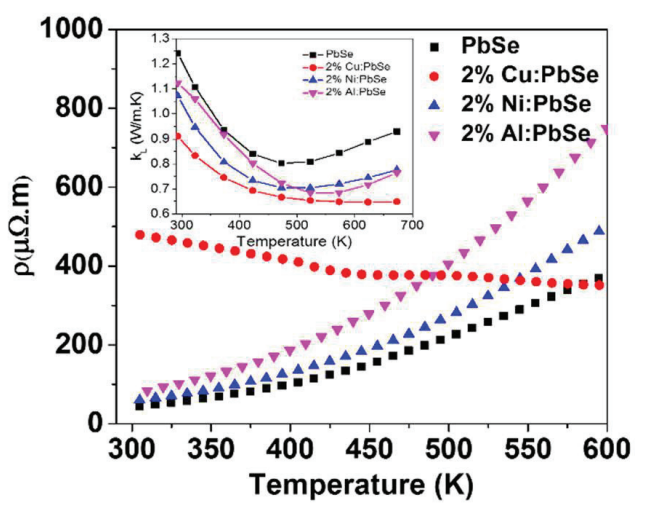

Figure 2: Temperature dependence of electrical conductivity of $\mathrm{PbSe}: \mathrm{M}_{\mathrm{x}}(\mathrm{M}: \mathrm{Al}, \mathrm{Ni}, \mathrm{Cu} ; 0 \leq \mathrm{x} \leq 0.02)$ (Inset figure represents lattice thermal conductivity)

The temperature dependence of resistivity is studied in Figure 2, where a monotonic rise in the resistivity with temperature indicates a typical degenerate conduction for $\mathrm{PbSe}: \mathrm{M}_{\mathrm{x}}$ (M: Al, Ni; $\left.0 \leq \mathrm{x} \leq 0.02\right)$. Additionally, the increase of resistivity at high temperature could be described with carrier-phonon interaction, as the mobility decreases with carrierphonon scattering. Therefore, in $\mathrm{Al} / \mathrm{Ni}$ doped $\mathrm{PbSe}$ the resistivity increases with temperature and follows the degenerate semiconductor characteristics. In fact the donor behavior of $\mathrm{Cu}$ dopant follows the non-degenerate characteristic and with this the decreasing trend of resistivity with temperature has been noticed. Through the alloy/point scattering the lattice thermal conductivity of doped PbSe varies as, $\kappa_{\mathrm{Cu}}<\kappa_{\mathrm{Ni}}<\kappa_{\mathrm{Al}}$. Hence, the intrinsic nature of dopants severally influences the thermoelectric properties.

\section{References}

1. Q. Zhang, F. Cao, K. Lukas, W. Liu, K. Esfarjani, C. Opeil, D. Broido, D. Parker, D. J. Singh, G. Chen, Z. F. Ren, J. Am. Chem. Soc. 134 (2012) 17731.

2. K. Biswas, J. He, I. D. Blum, C. I. Wu, T. P. Hogan, D.

N. Seidman, V. P. Dravid, M. G. Kanatzidis, Nature 489 (2012) 414.

3. C. Gayner, K. Kar, J. Appl. Phys. 117 (2015) 103906. 